\title{
Design of Rectangular Microstrip Patch Antenna Incorporated with Innovative Metamaterial Structure for Dual band operation and Amelioration in Patch Antenna Parameters with Negative $\mu$ and $\varepsilon$
}

\author{
Bimal Garg, Rahul Dev Verma, Ankit Samadhiya \\ Department of Electronics Engineering, Madhav Institute of Technology and \\ Science, Gwalior, India \\ E-mail: \\ bimalgarg@yahoo.com,rahuldev_verma@yahoo.co.in,ankit.samadhiya1987@gm \\ ail.com

\begin{abstract}
In this work a dual band rectangular microstrip patch antenna along with the innovative metamaterial structure is proposed at a height of $3.2 \mathrm{~mm}$ from the ground plane, which consists of a rectangular geometry incorporated with c shaped structure. This work is mainly focused on increasing the potential parameters of microstrip patch antennas and analyzing the dual band operation of proposed antenna. The proposed antenna is designed to resonate at $2.478 \mathrm{GHz}$ and $2.919 \mathrm{GHz}$ frequency. The impedance bandwidth of the patch antenna along with the proposed metamaterial structure at $2.478 \mathrm{GHz}$ is improved by $20.4 \mathrm{MHz}$ and return loss is reduced by $20.128 \mathrm{~dB}$. At $2.919 \mathrm{GHz}$ the impedance bandwidth is improved by $25.4 \mathrm{MHz}$ and return loss is reduced by $19.564 \mathrm{~dB}$. For verifying that the proposed metamaterial structure possesses Negative values of Permeability and Permittivity within the operating frequency ranges, Nicolson-RossWeir method (NRW) has been employed. For simulation purpose CST-MWS Software has been used.
\end{abstract}

Keywords: Dual band operation, Impedance bandwidth, Nicolson-Ross-Weir (NRW), Rectangular Microstrip Patch Antenna (RMPA), Return loss. 


\section{Introduction}

This is the world of wireless communication systems, in this world RMPA plays a very important role. In spite of having a lot of advantages (low profile, low cost and omni directional radiation patterns etc.), it has some drawbacks like narrow bandwidth and low gain [17]. Several researches have been done to overcome their drawbacks. In this context Victor Vesalago [1], [7] introduced the theoretical concept of metamaterial. According to the theory of Vesalago, these materials are generally artificial materials used to provide properties which are not found in readily available materials in nature [6], [13]. Later on J.B. Pendry and his colleagues, [4] added more information into the theory of metamaterial. They proved that the array of metallic wires can be used to obtain negative permittivity and split ring resonators for negative permeability. Later in year 2001 smith et al [5] fabricated a structure, which was a composition of split ring resonator and thin wire and it is named as LHM [11], [14].

In this work "Rectangular geometry incorporated with c shaped structure" as a metamaterial structure has been introduced for ameliorating the patch antenna parameters. It has also been seen that with these improvements this structure also possesses double negative properties within the operating frequency ranges.

\section{Design Specifications}

The RMPA parameters are calculated from the formulas given below.

Desired Parametric Analysis [2], [3]

2.1 Calculation of Width (W).

$$
\mathrm{W}=\frac{1}{2 \mathrm{f}_{\mathrm{r}} \sqrt{\mu_{0} \varepsilon_{0}}} \sqrt{\frac{2}{\varepsilon_{\mathrm{r}}+1}}=\frac{\mathrm{C}}{2 \mathrm{f}_{\mathrm{r}}} \sqrt{\frac{2}{\varepsilon_{\mathrm{r}}+1}}
$$

Where

$\mathrm{c}=$ free space velocity of light

$\varepsilon_{\mathrm{r}}=$ Dielectric constant of substrate

2.2 The effective dielectric constant of the rectangular microstrip patch antenna.

$$
\varepsilon_{\mathrm{eff}}=\frac{\varepsilon_{\mathrm{r}}+1}{2}+\frac{\varepsilon_{\mathrm{r}}-1}{2}\left(\frac{1}{\sqrt{1+\frac{12 \mathrm{~h}}{\mathrm{w}}}}\right)
$$

2.3 The actual length of the Patch $(L)$.

$$
\mathrm{L}=\mathrm{L}_{\mathrm{eff}}-2 \Delta \mathrm{L}
$$


Where

$$
\text { Leff }=\frac{C}{2 f_{r} \sqrt{\varepsilon_{e f f}}}
$$

2.4 Calculation of Length Extension.

$$
\frac{\Delta \mathrm{L}}{\mathrm{h}}=0.412 \frac{\left(\varepsilon_{\text {eff }}+0.3\right)\left(\frac{\mathrm{w}}{\mathrm{h}}+0.264\right)}{\left(\varepsilon_{\mathrm{eff}}-0.258\right)\left(\frac{\mathrm{w}}{\mathrm{h}}+0.8\right)}
$$

\section{Analysis of Rectangular Microstrip Patch Antenna and Metamaterial Structure with Simulated Results}

The Rectangular Microstrip Patch Antenna is designed on FR-4 (Lossy) substrate. The parameter specifications of rectangular microstrip patch antenna are mentioned in table 1 . These are calculated from the above discussed formulae.

Table 1: Rectangular Microstrip Patch Antenna Specifications

\begin{tabular}{ccc}
\hline & Dimensions & Unit \\
\hline $\begin{array}{c}\text { Dielectric } \\
\text { Constant }(\epsilon \mathrm{r})\end{array}$ & 4.3 & - \\
$\begin{array}{c}\text { Loss Tangent } \\
(\tan \partial)\end{array}$ & 0.02 & - \\
Thickness (h) & 1.6 & $\mathrm{~mm}$ \\
Operating & $2.478 \& 2.919$ & $\mathrm{GHz}$ \\
Frequency & 23.69 & $\mathrm{~mm}$ \\
Length (L) & 30.71 & $\mathrm{~mm}$ \\
Width (W) & 4.28 & $\mathrm{~mm}$ \\
Cut Width & 10 & $\mathrm{~mm}$ \\
Cut Depth & 25.357 & $\mathrm{~mm}$ \\
Path Length & 2.8 & $\mathrm{~mm}$ \\
Width Of Feed & &
\end{tabular}

Dimensional view of a rectangular microstrip patch antenna (RMPA), with a microstrip feed line is shown in Fig.1. 


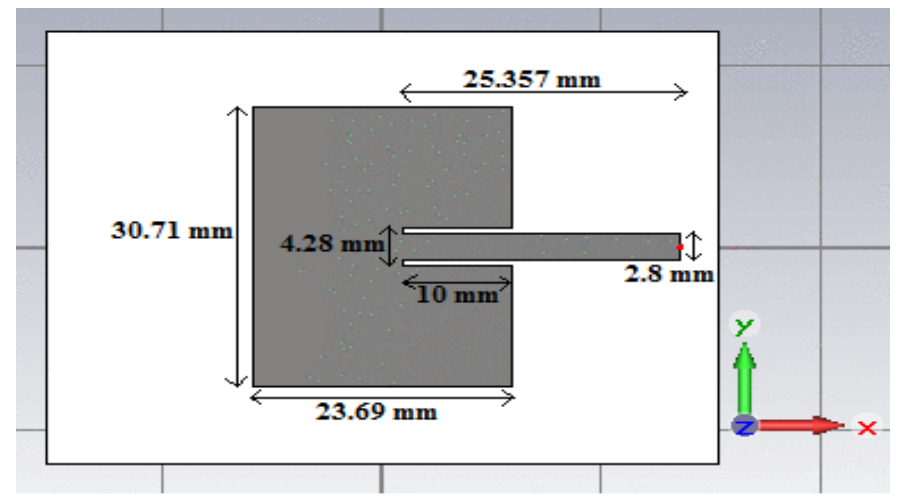

Fig.1: Rectangular patch antenna at $2.919 \mathrm{GHz}$.

Return loss $S_{11}$ and Impedance Bandwidth of Rectangular Microstrip Patch Antenna is shown in Fig.2.

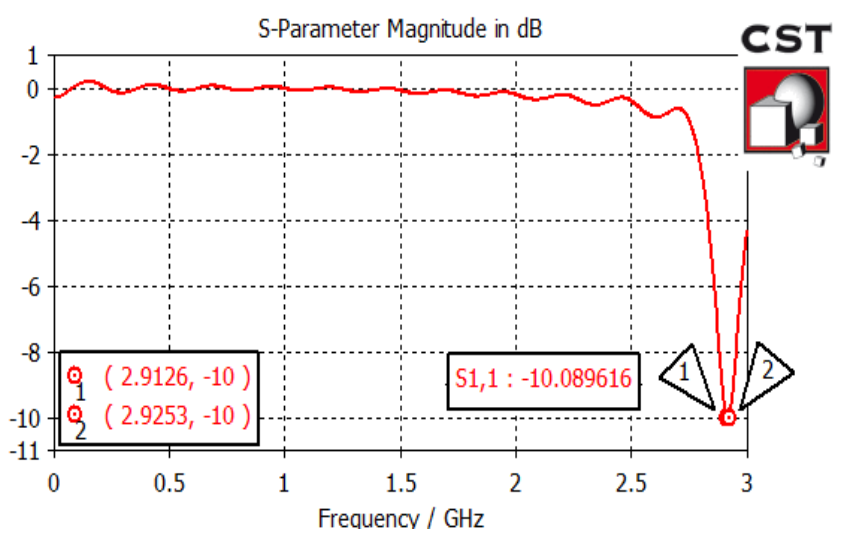

Fig.2: Simulation of Return loss $S_{11}$ and impedance bandwidth of RMPA.

In this paper "Rectangular geometry incorporated with c shaped structure" as a metamaterial structure has been introduced. The Dimensional view of this design is shown in the Fig.3.

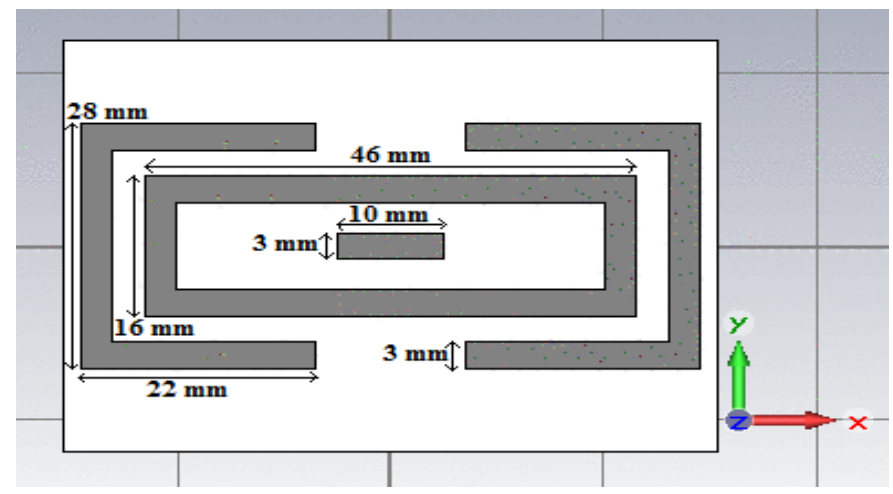

Fig.3: Design of proposed metamaterial structure. 
In order to calculate the S-Parameters, the proposed metamaterial structure is placed between the two waveguide ports [15], [16] at the left and right hand side of the X axis. In Fig.4, Y-Plane is defined as Perfect Electric Boundary (PEB) and Z-Plane is defined as the Perfect Magnetic Boundary (PMB) to create internal environment of waveguide. The simulated S-Parameters are then exported to Microsoft Excel Program for verifying the Double-Negative properties of the proposed metamaterial structure.

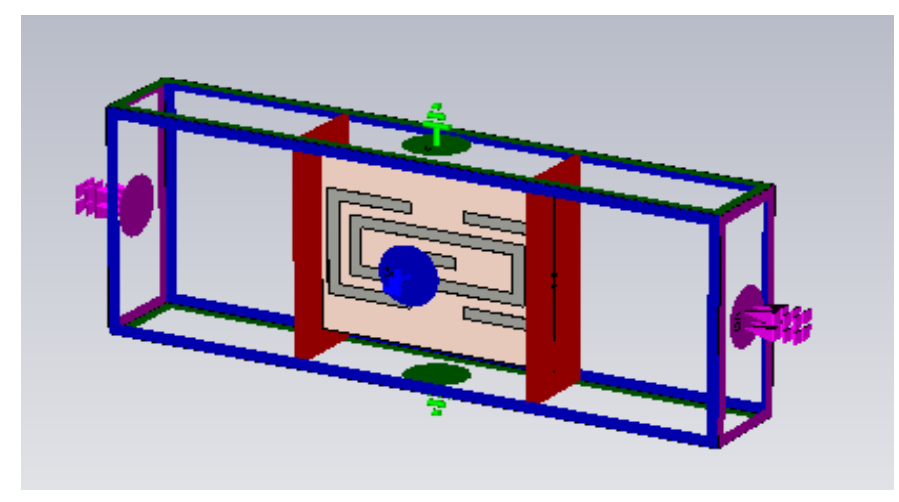

Fig.4: Proposed metamaterial structure between the two waveguide ports.

Nicolson-Ross-Weir (NRW) technique [8], [10] has been used for obtaining the values of permittivity and permeability.

\subsection{NRW Method}

Equations used for calculating permittivity \& permeability using NRW approach [9]-[10], [12], [18]-[19].

$$
\begin{aligned}
& \mu_{r}=\frac{2 . c(1-v 2)}{\omega \cdot d \cdot i(1+v 2)} \\
& \varepsilon_{r}=\mu_{r}+\frac{2 . S 11 . c . i}{\omega . d} \\
& \mathrm{v}_{2}=\mathrm{s}_{21}-\mathrm{s}_{11}
\end{aligned}
$$

Where

$\varepsilon r=$ Permittivity

$\mu r=$ Permeability

$\omega=$ Frequency in Radian,

$\mathrm{d}=$ Thickness of the Substrate,

$\mathrm{c}=$ Speed of Light, and

$v_{2}=$ Voltage Minima 
The obtained values of Permeability within the operating frequency range from the MS-Excel Program are given in table $2 \& 3$, whereas Fig.5 shows the graph between permeability \& frequency.

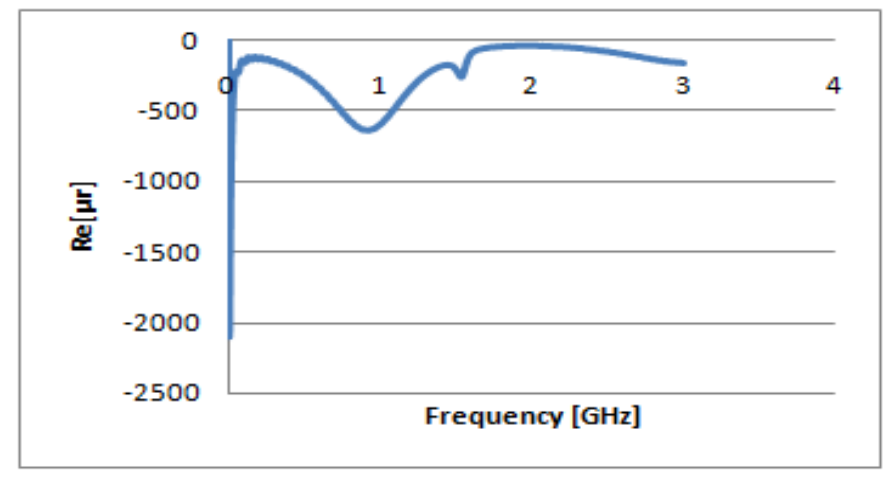

Fig.5: Permeability versus Frequency Graph.

Table 2

\begin{tabular}{|c|c|c|}
\hline Frequency $[\mathrm{GHz}]$ & Permeability $[\mu \mathrm{r}]$ & $\operatorname{Re}[\mu \mathrm{r}]$ \\
\hline 2.4719999 & $-77.6279592755951-120.483096386954 \mathrm{i}$ & -77.628 \\
\hline 2.4749997 & $-78.5709812270403-120.77275800359 \mathrm{i}$ & -78.571 \\
\hline 2.4780002 & $-79.5058155897525-120.836395528798 \mathrm{i}$ & -79.506 \\
\hline 2.4809999 & $-80.3383893390709-120.699062702999 \mathrm{i}$ & -80.338 \\
\hline 2.484 & $-80.9941950999083-120.42416034869 \mathrm{i}$ & -80.994 \\
\hline
\end{tabular}

Table 3

\begin{tabular}{|c|c|c|}
\hline Frequency $[\mathrm{GHz}]$ & Permeability $[\mu \mathrm{r}]$ & $\operatorname{Re}[\mu \mathrm{r}]$ \\
\hline 2.9129999 & $-155.514058648021-95.999009798791 i$ & -155.51 \\
\hline 2.9159999 & $-156.072462729328-94.6457868940843 i$ & -156.07 \\
\hline 2.9189997 & $-156.298256755299-93.283408081249 i$ & -156.3 \\
\hline 2.9219995 & $-156.222331425842-92.0503747818737 \mathrm{i}$ & -156.22 \\
\hline 2.925 & $-155.930279086631-91.057907250405 i$ & -155.93 \\
\hline
\end{tabular}


The obtained values of Permittivity within the operating frequency range from the MS-Excel Program are given in table $4 \& 5$. Whereas Fig. 6 shows the graph between permittivity \& frequency.

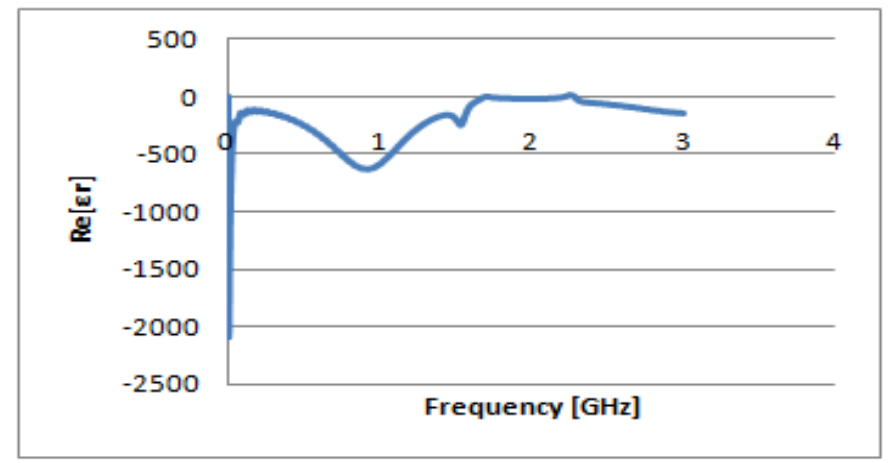

Fig.6: Permittivity versus Frequency Graph.

Table 4

\begin{tabular}{|c|c|c|}
\hline Frequency $[\mathrm{GHz}]$ & Permittivity $[\varepsilon r]$ & $\operatorname{Re}[\varepsilon r]$ \\
\hline 2.4719999 & $-66.5299915466665-103.888583462612 \mathrm{i}$ & -66.53 \\
\hline 2.4749997 & $-67.3661874821544-103.970817645799 \mathrm{i}$ & -67.37 \\
\hline 2.4780002 & $-68.1695365473869-103.848448363677 \mathrm{i}$ & -68.17 \\
\hline 2.4809999 & $-68.8548096120611-103.555091870662 \mathrm{i}$ & -68.85 \\
\hline 2.484 & $-69.3590426749572-103.158436106361 \mathrm{i}$ & -69.36 \\
\hline
\end{tabular}

Table 5

\begin{tabular}{|c|c|c|}
\hline Frequency $[\mathrm{GHz}]$ & Permittivity $[\varepsilon r]$ & $\operatorname{Re}[\varepsilon r]$ \\
\hline 2.9129999 & $-140.370522431298-76.4205114390454 \mathrm{i}$ & -140.37 \\
\hline 2.9159999 & $-140.831595881022-75.0277352400415 \mathrm{i}$ & -140.83 \\
\hline 2.9189997 & $-140.953096453185-73.6714773313376 \mathrm{i}$ & -140.95 \\
\hline 2.9219995 & $-140.785618512081-72.4894683061111 \mathrm{i}$ & -140.79 \\
\hline 2.925 & $-140.432775967197-71.5840234492923 \mathrm{i}$ & -140.43 \\
\hline
\end{tabular}

Rectangular Microstrip Patch Antenna with proposed metamaterial is given below in Fig.7.

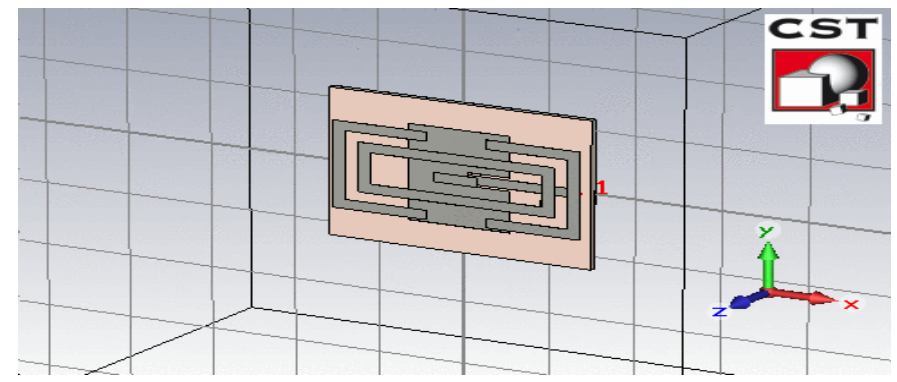

Fig.7: Rectangular Microstrip Patch Antenna with proposed metamaterial structure. 
Return loss $S_{11}$ and Impedance Bandwidth of Rectangular microstrip Patch Antenna with proposed metamaterial structure is shown in Fig.8.

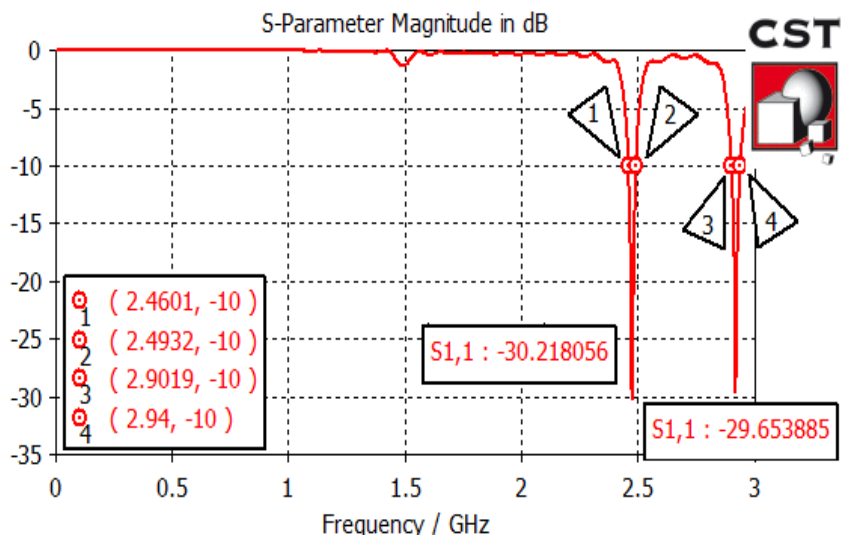

Fig.8: Simulation of Return Loss $S_{11}$ and impedance bandwidth of RMPA with proposed metamaterial structure.

This Return loss pattern within the simulated frequency range has been obtained from CST-MWS software, for verifying this result, hardware has been fabricated on PCB. After the fabrication of proposed antenna the antenna parameters like return loss and bandwidth are measured on the spectrum analyzer. Setup which is used for antenna parameters measurement is shown in Fig.9.

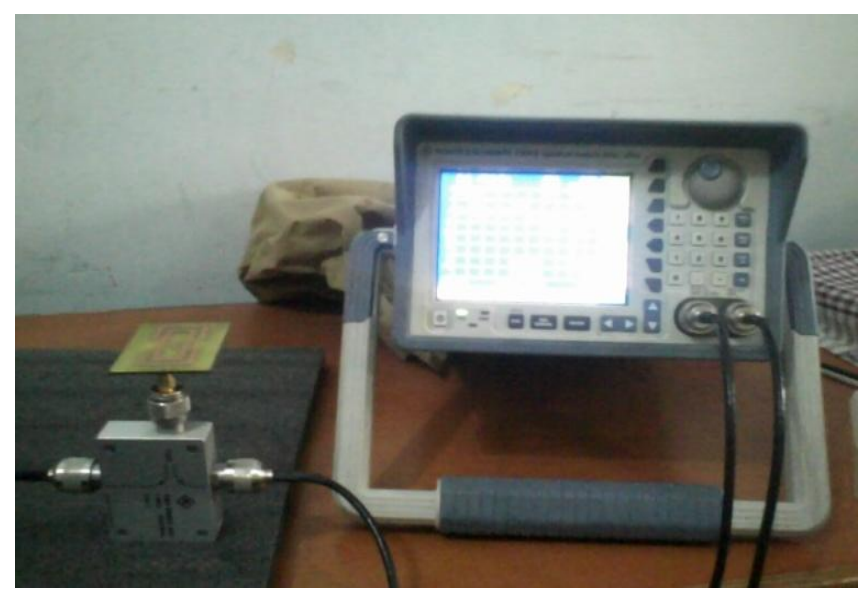

Fig.9: Setup for measurement of antenna parameters.

Dual band operation of the proposed antenna can be verified from the Graph given in Fig.10. This graph has been plotted by taking the values of return loss (in $\mathrm{dB}$ ) within the operating frequency range obtained from the Frequency analyzer. 


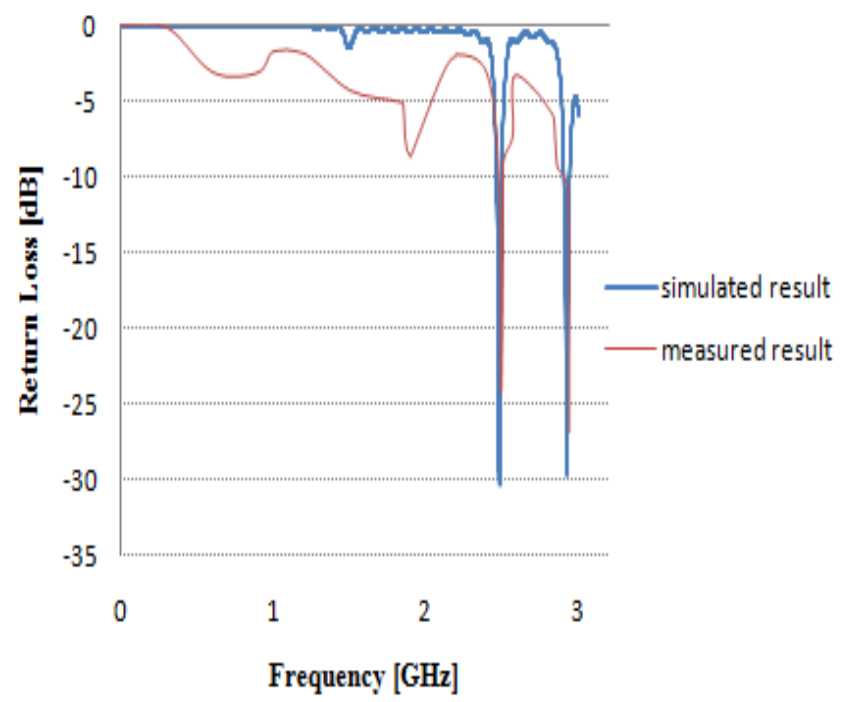

Fig.10: Graph between Return Loss $S_{11}$ and bandwidth.

This graph shows that there is a slight variation in operating frequencies. According to this graph the return loss and bandwidth at $2.486 \mathrm{GHz}$ are $24.252 \mathrm{~dB} \& 27.975 \mathrm{MHz}$ and at $2.933 \mathrm{GHz}$ these values are $-26.957 \mathrm{~dB} \& 34.978$ $\mathrm{MHz}$ respectively.

S-Parameter Smith Chart of Rectangular Microstrip patch antenna with proposed metamaterial structure is shown in Fig. 11.

S-Parameter Smith Chart

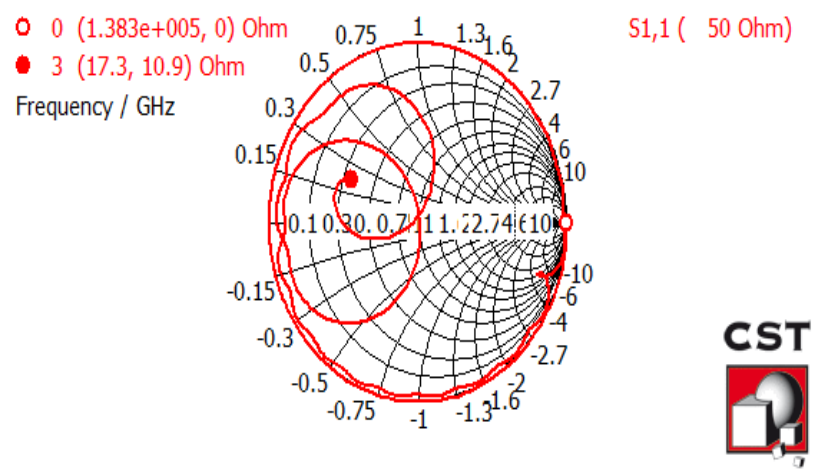

Fig.11: Smith Chart of RMPA with proposed metamaterial structure.

This Fig. shows the impedance variation within the simulated frequency range and on the basis of smith chart information about impedance matching can be easily obtained. 


\section{Simulation Results}

In this section, the simulated results are presented. When the RMPA with the proposed metamaterial Structure is simulated using CST-MWS software, it has been found that the potential parameters of the proposed antenna increases significantly in comparison to RMPA alone. This is clear from Fig. 2 \& Fig.8 that at $2.919 \mathrm{GHz}$ operating frequency return loss is reduced by $19.564 \mathrm{~dB} \&$ bandwidth is increased by $25.4 \mathrm{MHz}$. This antenna can also be operated at 2.478 $\mathrm{GHz}$ as it provides dual band operation. At $2.478 \mathrm{GHz}$ the values of Return loss and bandwidth are $-30.218 \mathrm{~dB} \& 33.1 \mathrm{MHz}$ respectively. Smith Chart in figure 11 shows the impedance variation within the simulated frequency range. Fig.5 \& Fig.6 verifies the Double Negative properties of the proposed metamaterial Structure.

\section{Conclusion}

On the basis of the simulated results it is observed that the RMPA parameters has improved significantly by employing proposed metamaterial structure at $3.2 \mathrm{~mm}$ layer from the ground plane of the antenna. There are very less variations have been observed between the measured results (fabricated RMPA with proposed metamaterial structure) and the simulated result of proposed antenna. Along with these improvements it has also been verified that this structure satisfies Double Negative property within the operating frequency ranges.

\section{Future Development}

For enhancing the bandwidth and reducing the return loss of RMPA, metamaterial can be designed by using different substrate and structure. Antenna performance can also be analysed by using different structure of patches and feeding techniques.

\section{References}

[1] V. G. Veselago, "The electrodynamics of substances with simultaneously negative values of $\mu$ and $\varepsilon "$, Sov. Phys. Uspekhi, vol. 10, no. 4 (1968), pps. $509-514$.

[2] Constantine A. Balanis, Antenna Theory and Design, John Wiley \& Sons, Inc., 1997.

[3] W.L. Stutzman, G.A. Thiele, Antenna Theory and design, John Wiley \& Sons, 2nd Ed., New York, 1998.

[4] J.B. Pendry, A.J. Holden, D.J. Robbins, W.J. Stewart, "magnetism from conductors and enhanced nonlinear phenomena" IEEE Trans. Micro Tech. vol.47 no.11 (1999), pp.2075-2081. 
[5] D.R. Smith, W.J. Padilla, D.C. Vier, S. C. Nemat-Nasser, and S. Schultz, Composite medium with simultaneously negative permeability and permittivity, Phys Rev Lett 84 (2000), pp. 4184-4187.

[6] J.B. Pendry, Negative refraction males a prefect lens, Phys Rev Lett, 85 (2000), pp.3966-3969.

[7] Nader Engheta, Richard W. Ziolkowski, "Metamaterial Physics \& Engineering Explorations", Wiley-IEEE Press, June 2006.

[8] Ahmad A. Sulaiman, Ahmad S. Nasaruddin, "Bandwidth Enhancement in patch antenna by metamaterial substrate", European Journal of scientific research, 2010.

[9] Huda A. Mazid, Mohammad Kamal A. Rahim, Thelasa Masri, "Left-handed metamaterial design for microstrip antenna application", IEEE International RF and Microwave conference, 2008.

[10] Ziolkowski, R. W., "Design, fabrication, and testing of double negative metamaterials," IEEE Transactions on Antennas and Propagation, Vol. 51, No. 7 (2003), pp.1516-1529.

[11] Wu, B-I, W. Wang, J. Pacheco, X. Chen, T. Grzegorczyk, and J.A. Kong, "A study of using metamaterials as antenna substrate to enhance gain," Progress in Electromagnetic Research, PIERS 51 (2005), pp. 295-328.

[12] H.A. Majid, M.K.A. Rahim and T. Marsi, Microstrip Antenna gain enhancement using left-handed metamaterial structure, progress in Electromagnetic Research M. Vol.8 (2009), pp. 235-247.

[13] Bimal Garg, Rahul Tiwari, Ashish Kumar and Tilak Chitransh, "Design of factored ' $\mathrm{X}$ ' shaped metamaterial structure for enhancement of patch antenna gain", International Conference on Communication Systems and Network Technologies 2011.

[14] Shah Nawaz Burokur, Mohamed Latrach and Sergre Toutain, "Theoritical Investigation of a Circular Patch Antenna in the Presence of a Left-Handed Mematerial", IEEE Antennas and Wireless Propagation Letters, Vol. 4, 2005.

[15] Silvio Hrabar, Juraj Bartolic, "Backward Wave Propagation in Waveguide Filled with Negative Permeability Meta Material”, Antennas and Propagation Society International Symposium, vol. 1 (2003), pp. 110 - 113.

[16] Silvio Hrabar, Gordan Jankovic, Berislav Zivkovic, Zvonimir Sipus, "Numerical and Experimental Investigation of Field Distribution in Waveguide Filled with Anisotropic Single Negative Metamaterial”, Applied electromagnetics and communications (ICEcom), (2005), pp. 1- 4.

[17] Vikas Gupta, B.S. Dhaliwal "Performance Enhancement of Recangular Microstrip Patch Antenna by Loading Complementary Split Ring Resonator in the Patch", International Journal of Electronics Engineering, 3 (1), (2011), pp. $141-143$.

[18] Ankit Samadhiya, Rahul Dev Verma, "Design of SSRR based Metamaterial Structure for Amelioration in Patch Antenna Parameters with Negative $\mu$ and $\varepsilon$ ". International Conference on Electronic Communication \& Instrumentation, Jhansi UP, 6-7 April 2012. 
[19] Bimal Garg, Ankit Samadhiya, Rahul Dev Verma, "Design of Double-F Metamaterial Structure for Enhancing Bandwidth of Patch Antenna With Negative $\mu$ And $\varepsilon$ ". International Conference on Communication Systems and Network Technologies (CSNT-2012), Rajkot (Gujrat), 11-13 May 2012. 